\title{
Prevalence of Venereophobia among Patients of Non- Venereal Genital Conditions- A Cross-Sectional Hospital Based Study from Nepal
}

\author{
Vikash Paudel ${ }^{1,2}$, Deepa Chudal ${ }^{3}$, Upama Paudel ${ }^{2}$, Dwarika Prasad Shrestha ${ }^{2}$ \\ ${ }^{1}$ National Medical College, Parsa, Nepal; ${ }^{2}$ Maharajgunj Medical Campus, Institute of Medicine, Kathmandu, Nepal; \\ ${ }^{3}$ Nepal Police Hospital, Kathmandu, Nepal
}

\begin{abstract}
Background: Venereophobia is the fear of getting venereal diseases or sexually transmitted diseases. This study was carried out to determine the prevalence and describe the varying clinical pattern of dermatoses among patients with venereophobia in non-venereal genital conditions.

Materials and Methods: This was a hospital-based, prospective, cross-sectional observational study conducted in a tertiary center in Kathmandu, Nepal, over a period of one year. A nonprobability purposive convenient sampling technique was used to select the samples. Two hundred patients were enrolled in the study. Ethical approval was taken prior to the study. A detailed history along with a complete cutaneous examination was carried out in all patients and recorded in preformed proforma. Patients with symptoms and clinical signs of sexually transmitted infections were excluded from the study.

Results: The prevalence of venereophobia among non-venereal dermatosis was $18 \%$. The mean age of the patient with venereophobia was $32 \pm 11.6$ years. The male to female ratio was $17: 2$. About $72 \%$ of the total patients were married. The most common symptoms of patients with venereophobia were genital itching, whereas about $44 \%$ were asymptomatic. The common dermatological disorders associated with venereophobia were pearly penile papules, genital vitiligo, irritant contact dermatitis. Three fourth of the patient with venereophobia had multiple sexual exposures.

Conclusions: Venereophobia is an important issue to be focused on patients with genital dermatosis and a significant number of patients might have venereophobia even in non-venereal genital dermatoses. A proper genital and psychiatric evaluation might prevent misdiagnosis and complications.
\end{abstract}

Key words: Phobia; Sexually transmitted infections; Venereophobia

\section{Introduction}

G enital skin has normal characteristics, besides related to sex and excretion, the dermatoses in these areas might also be related to general pathophysiology, urinary disease, and venereal diseases. ${ }^{1,2}$ Patient with a lesion in the genital might visit varied specialists. $^{3}$ Improving knowledge and attitudes towards sexually transmitted infections (STI) has led to an increase in STI clinic visits. They might

Funding: No

Conflict of Interest: No

\section{Address of Correspondence}

Dr. Vikash Paudel, MD

ORCID ID: 0000-0001-8729-052X

Assistant Professor, Department of Dermatology, National Medical College

Postal Address: Birgunj-19, Bhediyahi, Parsa, State 2, Nepal

E-mail: vikashpoudel@iom.edu.np, +97798499948600 also have venerophobia which is the unnatural fear of STI. ${ }^{4}$

Any genital dermatoses pose serious diagnostic and therapeutic challenges, due to their bizarre

Date of Submission: $18^{\text {th }}$ June 2021

Date of Acceptance: $31^{\text {st }}$ August 2021

Date of Publication: $1^{\text {st }}$ October 2021

How to cite this article

Paudel V, Chudal C, Paudel U, Shrestha DP. Prevalence of Venereophobia among Patients of Non-Venereal Genital Conditions- A Cross-Sectional Hospital Based Study from Nepal. NJDVL 2021;19(2):34-8. https://doi.org/10.3126/njdvl. v19i2.39020.

\section{(c) (i)}

Licensed under CC BY 4.0 International License which permits use, distribution and reproduction in any medium, provided the original work is properly cited. 
presentation, privacy and hesitancy for checkups, embarrassment, and inability of necessary investigations to perform. ${ }^{2}$ Besides, these problems might disseminate to other areas, can later cause complications, hamper the quality of lives and lead to mental distress, feeling of guilt among patients. ${ }^{4}$

The exact incidence of fear of sexually transmitted diseases has less been reported. Very few published studies from Nepal have investigated non-venereal genital dermatosis (NGVD) and venerophobia. ${ }^{5-8}$ Thus, this study aims to investigate the epidemiological pattern of venerophobia among patients with NVGD.

\section{Methods}

This was a hospital-based, prospective, cross-sectional study conducted in the Department of Dermatology of the Institute of Medicine, Tribhuvan University Teaching Hospital, Kathmandu, Nepal, over a period of June 2014 to May 2015. Ethical approval was taken from the Institutional Review Board (IRB Reference No. 6-11-E/071/072) prior to study. Non-probability purposive sampling was used to select the samples. Two hundred consecutive patients with non-venereal genital dermatoses were enrolled in the study. All participants provided written informed consent for participation. Patients with ano-genital lesions were included in the study. Patients with symptoms and clinical signs of sexually transmitted infections were excluded from the study. The signs and symptoms of the STI included history of sexual contact and appearance of genital ulcer, discharge, swellings etc. The diagnosis was based on detailed history, clinical features, and appropriate investigations when required. The examination findings were noted and details were recorded in the prepared proforma. Statistical Package for Social Science (SPSS) 20 was used for statistical analysis. Descriptive statistics were utilized to compute the mean and standard deviation. The results were considered statistically significant at an alpha of $5 \%(p \leq 0.05)$.

\section{Results}

The hospital prevalence of NVGD was $0.93 \%$. Out of the two hundred patients with NGVD, 36 patients had venereophobia, thus the prevalence of venereophobia was $18 \%$. Among 36 patients, 32 were male and 4 female patients were female with male to female ratio of $17: 2$. The mean age of patients presenting with features of venereophobia was 32.2 years (SD+11.6, Range: 20-66 years). Their socio-demographic characteristics are shown in Table 1.

\section{Pattern of clinical complaints among patients}

The most common complaint was pruritus in both males and females, which was present in $80.5 \% \%$ of patients. The other common symptoms were pain, blisters, swelling, burning, sores, etc. About 44 percent of the patient were asymptomatic. (Figure 1)

All of them had sexual exposure and were heterosexuals. Three fourths of the patients have multiple sexual exposures. Different genital conditions were found to be associated with venerophobia. The common were pearly penile papules, vitiligo, ICD, Zoon balanitis, disease, Fordyce spot, etc. (Table 2)

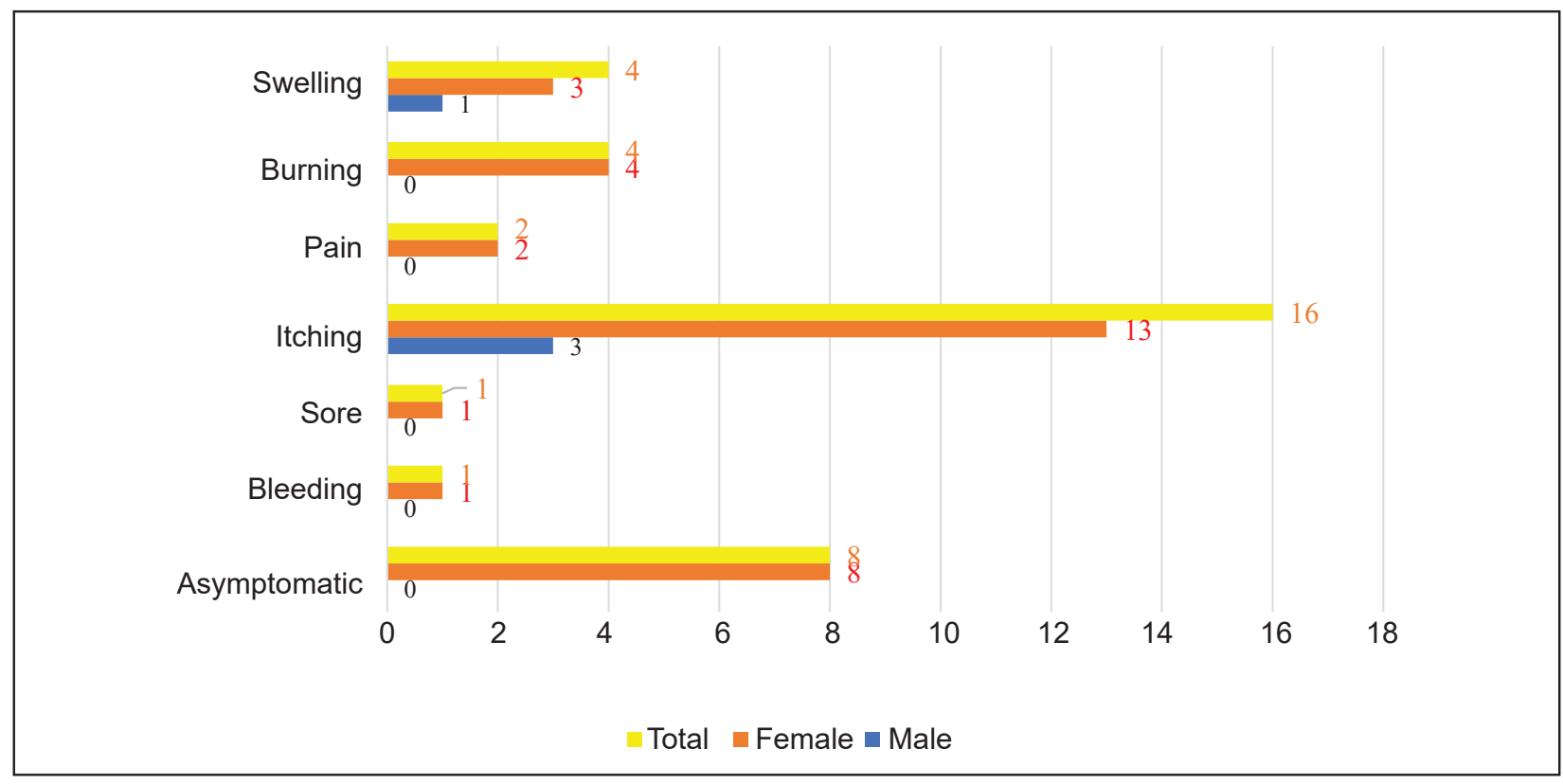

Figure 1: Clinical signs and symptoms of a patient with venereophobia 
Table 1: Socio-demographic profile of patients with venereophobia

\begin{tabular}{|c|c|c|c|}
\hline Characteristics & Categories & Frequency $(n=36)$ & Percentage \\
\hline \multirow{2}{*}{ Gender } & Female & 4 & 11.1 \\
\hline & Male & 32 & 88.9 \\
\hline \multirow{2}{*}{ Marital Status } & Married & 26 & 72.2 \\
\hline & Unmarried & 10 & 27.8 \\
\hline \multirow{6}{*}{ Educational Status } & Illiterate & 2 & 5.6 \\
\hline & Primary & 2 & 5.6 \\
\hline & Secondary & 8 & 22.2 \\
\hline & SLC & 10 & 27.8 \\
\hline & Graduate & 12 & 33.3 \\
\hline & Postgraduate & 2 & 5.6 \\
\hline \multirow{8}{*}{ Occupation } & Service & 5 & 13.9 \\
\hline & Farmer & 6 & 16.7 \\
\hline & Business & 9 & 25.0 \\
\hline & Security personnel & 3 & 8.3 \\
\hline & Students & 6 & 16.7 \\
\hline & Homemaker & 3 & 8.3 \\
\hline & Others & 1 & 2.8 \\
\hline & Labor migrants & 3 & 8.3 \\
\hline \multirow{2}{*}{ Religion } & Hindu & 30 & 83.3 \\
\hline & Buddhist & 6 & 16.7 \\
\hline \multirow{2}{*}{ Sexual Exposure } & Single & 9 & 25 \\
\hline & Multiple & 27 & 75 \\
\hline
\end{tabular}

Table 2: Various conditions associated with venerophobia.

\begin{tabular}{|l|c|c|c|c|}
\hline Diagnosis & Male $(\mathbf{n = 3 2 )}$ & Female $(\mathbf{n}=\mathbf{4})$ & Total $\mathbf{N = 3 6}$ & Percentage $\mathbf{1 0 0 \%}$ \\
\hline Pearly penile papule & 12 & 0 & 12 & 33.3 \\
\hline Vitiligo & 6 & 0 & 6 & 16.6 \\
\hline Irritant contact dermatitis & 3 & 1 & 4 & 11.1 \\
\hline Zoon's balanitis & 2 & 0 & 2 & 5.5 \\
\hline Fordyce spot & 1 & 1 & 2 & 5.5 \\
\hline Angiokeratoma & 1 & 0 & 1 & 2.7 \\
\hline Bartholin's cyst & 0 & 1 & 1 & 2.7 \\
\hline Lichen simplex chronicus & 0 & 1 & 1 & 2.7 \\
\hline Lymphedema of penis & 1 & 0 & 2 & 2.7 \\
\hline Phimosis & 2 & 0 & 1 & 5.5 \\
\hline Preputial cyst & 1 & 0 & 2 & 2.7 \\
\hline Epidermoid Cyst & 2 & 0 & 1 & 5.5 \\
\hline Hydrocele & 1 & 0 & 36 & 2.7 \\
\hline Total & 32 & 4 & & \\
\hline
\end{tabular}

\section{Discussions}

Our study was done to assess venereophobia and its clinical and epidemiological profile in patients with NVGD. These dermatoses are of paramount importance but considered an orphan disease. ${ }^{2}$ Because of the intimate nature of the problems, patients are frequently restrained about discussing problems with their healthcare providers. ${ }^{4}$ Though venereophobia is an important entity, they are mostly limited to age-old published literatures and large-scale studies on the prevalence of NVGD and venereophobia dermatoses are lacking. ${ }^{2,4,9}$

The hospital prevalence of NGVD in our study was $0.93 \%$ and which is similar to the study by Vinay $\mathrm{N}$ et 
al. where they had only $0.3 \% .{ }^{10}$ However, prevalence of venereophobia among NVGD in our study was $18 \%$, which is very high than that of the previous study where they had $2.4 \%$ only. ${ }^{10}$ The mean age group of the patient in our study was 32.2 years (SD 11.6 years) which ranged from 20 to 66 years. It was similar to the study by KC et al., Gyawalee et al. and Vinay et al.4,5,10 There were $72.2 \%$ of married and $27.8 \%$ unmarried patients, which is different from the study by KC S et al. ${ }^{5}$ This proves that NVGD and venereophobia can occur without sexual exposure but venerophobia commonly seen in patients with multiple sexual exposure. Majority of the patients in our study were males which was common in other similar studies. ${ }^{5,6,10}$ This is possibly due to the anatomy of male genitalia, and influence towards sexual activity among males, male dominated society, and commercial sexual seeking behavior of males as in other studies. 4,5,10,11 The study by Vinay et al. did not report any cases of venereophobia in women and most studies had venereophobia significantly higher in males. ${ }^{10}$

Regarding the common presenting complaints in our study, itching was the most common, occurring in $80.5 \%$ of patients. Itching was also the commonest presenting complaint in various studies. ${ }^{4,10,12}$ The other common symptoms were pain, blisters, swelling, burning, sores, etc. Other articles had skin lesions with discomfort and white sloughs in their studies followed by genital itching. ${ }^{4}$

Among the patients with venerophobia, 27 (75\%) had multiple sexual partners. In other studies, also, multiple sexual exposure was seen $32-39 \%$ and even in commercial sex workers. ${ }^{5,10,12,13}$

Pearly penile papules, genital vitiligo and dermatitis were the common concerning diagnosis in patients who had venereophobia. These are commonly seen NVGD reported in many studies. Pearly penile papules are flesh colored papules which are normal

\section{References}

1. Sharma VK, Khandpur S. Epidemiology of sexually transmitted diseases. In: Sharma VK, editor. Sexually Transmitted Diseases and AIDS. New Delhi: Viva Books Pvt Ltd; 2003.

2. Griffiths $C$, Barker J, Bleiker T, Chalmers D, Bunker $\mathrm{CB}$, Porter W. The genital, perianal and umbilical regions. In: Griffiths C, Barker J, Bleiker T, Chalmers D, eds. Rook's Textbook of Dermatology. 9th ed. Wiley-Blackwell, 2016. https://doi. org/10.1002/9781444317633.ch71 findings located circumferentially around the glans. ${ }^{4,5,8}$ The results are similar to the study performed by Michajlowski et al. ${ }^{13}$

Pearly penile papules have been reported to cause various psychiatric illness in males causing venereophobia, hypochondiraisis, psychosis, anxiety, and schizophrenia. ${ }^{5-7,10-14}$ The reason for this lack of general anatomical knowledge could be because of decreased sex education. Similarly, Mahajan BB et al. had pointed out that pearly penile papules, spermatorrhea, sticky meatus, genital dyspigmentation are common presentations of venereophobia. ${ }^{4} \mathrm{~A}$ multidisciplinary approach to NGVD and venerophobia could be done to reduce the morbidity associated with it. $3,5,10$

This study was a hospital-based study, hence is not completely representative of the situation in the community. Limited sample size might be another limitation of our study.

\section{Conclusions}

The clinical presentation of NGVD could be bizarre so as venereophobia. The prevalence of these diseases might reflect only the tip of the iceberg. Venereophobia is associated with various dermatological conditions. The level of knowledge on normal anatomy and physiology of genitalia, STI, preventive measures and safe sexual activity is needed to reduce the stigma, morbidities and possibilities of complications associated with it.

\section{Acknowledgment}

The authors would like to thank all the participants in this study and all the faculties, residents, and staff of the Department of Dermatology and Venereology, Institute of Medicine, for their cooperation in conducting this study.

3. Ascott A, Chinthapalli S, Gibbon K. Unifying clinical care between specialties: a model for genital disease. J R Soc Med 2017;110(5):177-182. https://doi.org/10.1177/0141076817693598

4. Mahajan BB, Shishak M. An approach to venerophobia in males. Indian J Sex Transm Dis AIDS 2017 Jan-Jun;38(1):103-106. https://doi. org/10.4103/0253-7184.203441

5. Kc S, Adhikary M, Karn D. Clinical Scenario of Venerophobia in Patients Presenting in Outpatient Department. J Nepal Health Res Counc 2020 Nov;18(3):483-487. https://doi.org/10.33314/ jnhrc.v18i3.2764 
6. Gyawalee M, Pokhrel D. Pattern of sexually transmitted infections and sexual behavior in patients with genital symptoms. NJDVL 2016;12(1):20-7. https://doi.org/10.3126/njdvl. v12i1.10592

7. Joshi S, Shrestha S, Joshi A. Clinico-epidemiological profile of women with non-venereal vulval diseases: a hospitalbased observational study. NJDVL 2019;17(1):32-8. https://doi.org/10.3126/ njdvl.v12i1.10592

8. Kumar A, Pun J, Neupane D, Subedi S, Mohammad A, Sathian B. Non-veneral genital dermatoses: A study from Western Nepal. NJDVL 2020;18(1):1823. https://doi.org/10.3126/njdvl.v18i1.30313.

9. Kite EdC, Grimble A. Psychiatric aspects of venereal disease. Br J Vener Dis 1963;39(3):17380. https://doi.org/10.1136/sti.39.3.173

10. Vinay N, Ranugha PSS, Betkerur JB, Shastry V, Ashwini PK. Non-venereal genital dermatoses and their impact on quality of life-A cross-sectional study. Indian J Dermatol Venereol Leprol $2021 \mathrm{Apr}$ 12:1-6. https://doi.org/10.25259/ijdvl_329_18
11. Shrestha R, Karki P, Copenhaver M. Early sexual debut: a risk factor for STIS/HIV acquisition among a national representative sample of adults in Nepal. J Community Health 2016;41(1):70-7. https://doi.org/10.1007/s10900-015-0065-6

12. Saraswat PK, Garg A, Mishra D, Garg S. A study of pattern of nonvenereal genital dermatoses of male attending skin OPD at a tertiary care center. Indian J Sex Transm Dis AIDS 2014 Jul-Dec;35(2):129-34. https://doi.org/10.1007/s10900-015-0065-6

13. Michajłowski I, Sobjanek M, Michajłowski J, Włodarkiewicz A, Matuszewski M. Normal variants in patients consulted in the Dermatology Clinic for lesions of the male external genitalia. Cent European J Urol 2012;65(1):17-20. https:// doi.org/10.5173/ceju.2012.01.art5

14. Hafi B, Uvais NA, Latheef EN, Razmi MT, Afra TP, Aysha S. Venereophobia - a cognitive deception? Case reports with literature review. Our Dermatol Online 2020;11(e):e138.1-e138.5. https://doi. org/10.7241/ourd.2020e.138 